\title{
ECONOMETRIC MODELLING OF INFLUENCE OF LEVEL OF THE SOCIAL AND ECONOMIC INFRASTRUCTURE ON QUALITY OF LIFE OF THE POPULATION
}

\author{
Ilchenko Angelina ${ }^{1}$, Xiang Xiao Gang ${ }^{2}$, Stepanov Vladimir ${ }^{3}$ \\ ${ }^{I}$ Ivanovo State University of Chemical Technology, Russia, dr.ilchencko@yandex.ru \\ ${ }^{2}$ Wuhan Textile University, China, econom@isuct.ru \\ ${ }^{3}$ Central Economic-Mathematical Institute of the Russian Academy of Sciences, Russia, econom@isuct.ru
}

\begin{abstract}
In this article, the index approach to an estimation of situational multifactor economic categories is considered: a level of development of a social and economic infrastructure of region and population living conditions. Author's mathematical models of formation of the integrated estimated indexes formulated on principles of the factorial analysis of hierarchies are used. The constructed estimated integrated indexes form a basis of ranging of territories, both in an annual cut and in dynamics on years that, in turn, allows to analyse the change in ratings of territories (during 5-10 years): on a level of development of an infrastructure and quality of life of the population. Authors give results of computer modelling of an index of development of a social and economic infrastructure. Here authors use additional parameters for the measurement of an index of capital investments in an infrastructure. Further, authors model an index of quality of life of the population. Here the methods used are the analysis of hierarchies, the factorial analysis and a method of the main things a component. Then the interrelation analysis between tendencies of change of indexes through comparison of ranks of territories is made. Theoretical offers of authors are accompanied by quantitative results of modelling experiments on materials of 30 Chinese provinces for the period of 10 years period.
\end{abstract}

Keywords: infrastructure; quality of life; mathematical modelling; integrated indicator; ranging of territories

JEL code: H54; O18; R58; C02

\section{Introduction}

Infrastructure is the general physical condition of development of a society within the borders of some territory, as well as the material means for a social production and necessary services in public service of the inhabitants living in this territory. The infrastructure includes transport service, mail and telecommunications, water supply, business administrative services, scientific research and technical services, gardening, environment protection, cultural service, education, health services and other municipal services of public life.

The basic infrastructural means play a huge role in the acceleration of social and economic activity of the population and the development of its spatial distribution. For the state, it is important to provide normal, under modern requirements, infrastructure, but it means long-term and huge investments. However, further, infrastructural investments have property of the saved up capital. They give effect within many decades, improving a business climate and quality of life of the population in region territory (Kularathe, 2006; Mc Kinsey, 2009; Kondratyev, 2010).

The concrete maintenance of quality of life includes actual level of the income, level of personal consumption and consumption structure, social conditions and working conditions, degree of development of social security, quantity of kinds of leisure, public health services and education and so on.

Authors investigate the fundamental scientific problem lying on a joint of sciences - the economic theory and optimum control of public processes: a problem of objective quantitative measurement of 
quality of life as criterion of comparison of economic development of certain territories. In the world economic science, the hypothesis about dynamic interference of infrastructural investments and qualities of life of the population in borders of territorial and production agglomerations now was generated. However, there are no yet objective methods and mathematical models for the measurement of the development of a social and economic infrastructure and quality of life of territories. Hence, it is impossible to estimate the degree of influence of an infrastructure on a population standard of living and also to objectively define the priorities in directions of the state investment, for the elimination of a disbalance in development of territories.

The author's attention is directed towards the decision regarding the specific target within the limits of a problem: creation of a complex of mathematics and statistical models for the formation of system of integrated indicators of the quality of life, defined based on the official statistical information, for the purpose of perfection of an investment infrastructural policy of the state. On the basis of integrated indexes, authors do ranging of territories and give the analysis of two rating positions of regions of the country, with a $\log$ of delay of 5 years. The analysis shows how (during the previous period) infrastructural maintenance of territory influences the quality of life of the population (during the subsequent period, in 5 years).

In this article, the results of experimental check of a fundamental scientific hypothesis on the statistical information of China (30 regions for 10 years) are described. The offered methodology (models, algorithms and information technology) is theoretical base of tool means of support of operating decisions, which is a component of information and communication control systems of new generation.

\section{Literature Review}

The problem of joint measurement of the quality of life and condition of an infrastructure has no reflexion in the literature. However, each of the specified aspects of this problem has wide scientific discussion.

Since 1975, when professor Morris has offered for the first time the concept of an index of the quality of life, of the world literature many works under the analysis and comparison of internal and external standards of life, construction of system of indicators for qualitative research of a standard of life and its separate aspects (Aivazian, 2012) are published. The Russian, European and Chinese scientists, at calculation of indexes, take into consideration the objective factors to the statistical of sphere of services to construct the summary indicator, using principles of objective weighing. For example, Lin Nan (1987) and Lu Shu Hua (1992) used equal weight of factors, and on the contrary, He Chuan Qi, Zhou Chang Cheng and Feng Xiao Tian have proved the recommendations about the calculation of a non-equilibrium variant of model of the indicator of the vital standard, with reference to conditions of the Chinese economy.

The Russian school of thought of research of living conditions is presented by known economistmathematician Aivazian S.A. (2010-2012) and its followers: Bakumenko L.P., Borodkin F.M., Verbik M. Their results are concentrated to the analysis of structure of integrated indicators and statistical measurement of scales of making components.

The design procedure of an index of development of human potential was extended in world practice, offered by experts of the United Nations. The index varies from 0 to 1 , which allows ranging objectively territories on quality of life of the population (Kondratyev, 2010).

For the classification of territories based on the infrastructure level of development, now, there are no standard techniques. Creation of methodology of measurement of an infrastructure of regions is complicated, owing to the objective reasons. The main reasons - uncertainty of the concept and its structural elements, the official published data - are incommensurable and non-comparable amongst themselves. The problem of factorial uncertainty does not allow making a uniform integrated estimation of an infrastructure of territory; therefore, numerous scientific publications reflect only researches of separate sectors of 'infrastructural space'. 
The generalised estimations of influence of 'infrastructures as a whole' on economic growth do not exist, as there is no conventional measuring instrument (indicator) of a level of development of an infrastructure in territory (Kondratyev 2010). Ilchenko and Ma Jun (2012) are the first to put forward the idea of the integrated indicator of measurement of an infrastructure (index of development of a social and economic infrastructure, IDSEI) in 2012, then Ilchenko used for the first time IDSEI to measure the level of development of a social and economic infrastructure of some Russian regions in 2014 (Ilchenko 2014).

In this article, authors expand experiment scale to check up a scientific hypothesis on full information base: 30 provinces of China during 2009-2014.

\section{Methodology}

Authors use modern methods of mathematical and logic formalisation for the description of natural science processes:

- Mathematical and statistical methods used are the theory of statistical measurements and economic indexes, the factorial analysis, the theory of objective weighing and the analysis of multilevel hierarchies;

- Economic-mathematical methods used are classification of multidimensional supervision, cluster and discriminant analysis, optimum control models and scenary forecasting.

On the basis of these methods, authors offer original index models that are experimentally approved, using the official statistical information.

Thus, in the article, the attempt to unite studying of these two important phenomena becomes to conduct research on the influence of processes of investment in a social and economic infrastructure on the quality of life of people. The modern device of economic-mathematical modelling and means of experimental computer toolkit, in a combination to an easy approach to databases of national statistics of China, give the chance to solve this problem.

\section{Experimental Modelling}

Experimental modelling includes research for each province of China: 1) Calculation of an index of development of an infrastructure; 2) Calculation of an index of quality of life; 3) Construction of numbers of dynamics of all regions (ratings), for each index; 4) The analysis of rating positions of regions 'with the worst indexes', for revealing the influence of factors of 'quality of an infrastructure' on the 'quality of life in 5 years'; 5) The conclusion: a priority of regions in a choice of directions of infrastructural investment for the state forward planning.

Index of quality of social and economic infrastructure. Model IDSEI is intended for the analysis of development of social and economic infrastructure of the countries on the basis of an index method. On the basis of index calculation, model IDSEI allows to estimate a condition of an economic infrastructure in each separately taken region of any state. The model can be useful for working out the regional infrastructural policy of the national governments and for the creation of long-term investment plans on regional economic development and increasing the standard of living of the population. Authors offer appropriate updating of model for its application to the data of official statistics of the Government of the Peoples Republic of China in 2013 and 2014. The detailed substantiation of parameters is resulted in the previous author's works (Ilchenko \& Ma Jun 2012, Xiang Xiao Gang \& Ilchenko 2013 and Ilchenko 2014). Table 1 shows the structure of model and structure of statistical components.

The modelling information can be transformed to diagrams (an example on Fig. 1) with the use of SPSS software.

The received diagrams allow drawing an important conclusion: east coastal provinces of China have the developed economy and the provinces close to the western border have the big territories, but it is not enough manpower resources. The first of them show rather high values of IDSEI, whilst the 
western provinces characterised by backward economy and high level of environmental contamination show low values of a considered index. It is necessary to notice that the Chinese government can direct more investments into an infrastructure of western regions to raise the level of their economic development and to improve a state of environment.

Table 1. Structure of statistics of model IDSEI

\begin{tabular}{|c|c|c|}
\hline Indicators & Denomination of specific indicators & $\begin{array}{c}\text { The statistical parameters used to determine the } \\
\text { parameters }\end{array}$ \\
\hline 1 & 2 & 3 \\
\hline \multicolumn{3}{|c|}{ Socio-demographic component ( Isoc ) Isoc $=(\mathrm{Ip}+\mathrm{Ic}+\mathrm{Ih}+\mathrm{Ik}) / 4$} \\
\hline Ip & $\begin{array}{l}\text { The index of the regional GDP per } \\
\text { capita }\end{array}$ & The regional GDP per capita, unit: Yuan. \\
\hline \multirow[t]{2}{*}{ Ic } & \multirow{2}{*}{$\begin{array}{l}\text { The index of population education } \\
\text { and health services } \\
\mathrm{Ic}=(\mathrm{Ic} 1+\mathrm{Ic} 2) / 2\end{array}$} & $\begin{array}{l}\text { The number of teachers per thousand people, unit: } \\
\text { number. }\end{array}$ \\
\hline & & $\begin{array}{l}\text { The number of doctors per } 1000 \text { people, unit: } \\
\text { number. }\end{array}$ \\
\hline Ih & $\begin{array}{l}\text { The index of the per capita housing } \\
\text { area }\end{array}$ & The per capita housing area, unit: square metre. \\
\hline $\mathrm{Ik}$ & $\begin{array}{l}\text { The index of the economically active } \\
\text { population }\end{array}$ & The economically active population, unit: million. \\
\hline \multicolumn{3}{|c|}{ Industrial component $($ Iter $) ~ I t e r=(I t r+\mathrm{Iw}+\mathrm{Iz}) / 3$} \\
\hline \multirow{2}{*}{ Itr } & \multirow{2}{*}{$\begin{array}{l}\text { The index of the transportation } \\
\text { network }\end{array}$} & $\begin{array}{l}\text { The length of highway per } 1000 \text { people, unit: } \\
\text { kilometre. }\end{array}$ \\
\hline & & $\begin{array}{l}\text { The length of railway per } 1000 \text { people, unit: } \\
\text { kilometre. }\end{array}$ \\
\hline Iw & $\begin{array}{l}\text { The index of the freshwater } \\
\text { consumption }\end{array}$ & $\begin{array}{l}\text { The amount of the per capita water consumption, } \\
\text { unit: cubic metre. }\end{array}$ \\
\hline \multirow{2}{*}{$\mathrm{Iz}$} & \multirow{2}{*}{$\begin{array}{l}\text { The index of the ecological } \\
\text { environment. } I z=1-(\mathrm{Iz} 1+\mathrm{Iz} 2) / 2\end{array}$} & $\begin{array}{l}\text { The amount of exhaust gas emissions of sulphur } \\
\text { dioxide per capita, unit: kilogram. }\end{array}$ \\
\hline & & $\begin{array}{l}\text { The amount of wastewater discharged per capita, } \\
\text { unit: ton. }\end{array}$ \\
\hline $\begin{array}{l}\text { Integral index } \\
\text { IDSEI }=(\text { Iso }\end{array}$ & $\begin{array}{l}\text { cio-economic infrastructure (IDSEI) } \\
\text { er) } / 3\end{array}$ & \\
\hline
\end{tabular}

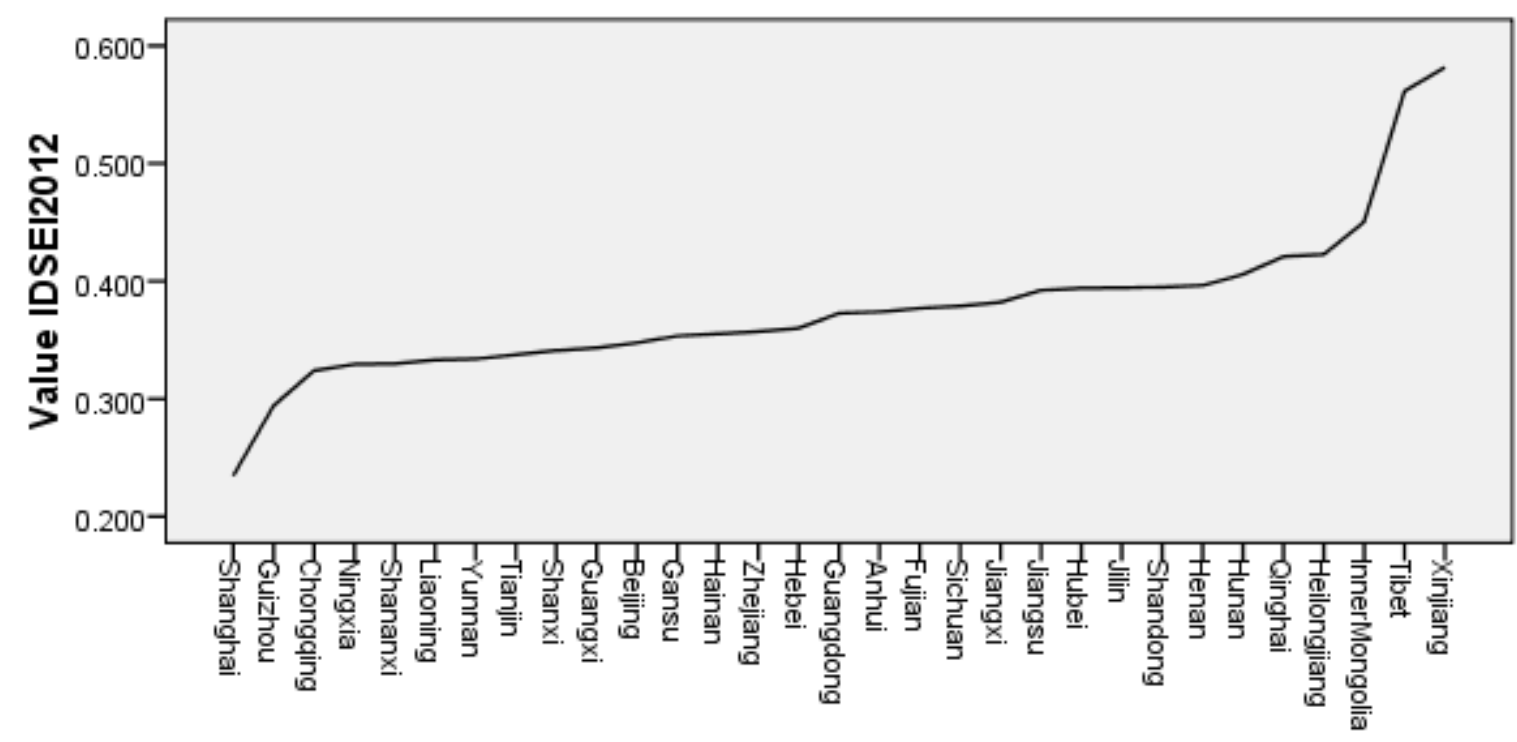

\section{Province}

Fig. 1. An index of development of a social and economic infrastructure (IDSEI) Municipalities of China - 2012 (authors' result) 
Working out a new index of the quality of life of population. The Index of quality of life (ILQ) assumes system of indicators of quality of life of the population. The estimation of quality of life is based on the consecutive aggregation of local statistics. The integrated index pays off as three-level hierarchy of linear polynomial. Weight factors for model components have equal weight at the bottom level and special weight at the second and third levels. Model ILQ includes 26 local indicators of quality of life from the official statistics (Xiang Xiao Gang. 2015). According to the structure of ILQ resulted in Table 2, the system of the equations for index definition will look as follows:

Table 2. Decomposition of structure of an integrated index of quality of life

\begin{tabular}{|c|c|c|c|c|}
\hline Level 1 & Level 2 & Level 3 & Level 4 & Signation \\
\hline \multirow{24}{*}{$\begin{array}{l}\text { Index of life } \\
\text { quality } \\
\text { (ILQ) }\end{array}$} & \multirow{13}{*}{$\begin{array}{l}\text { Index of } \\
\text { internal family } \\
\text { life quality } \\
\text { (IIFLQ) }\end{array}$} & \multirow{5}{*}{$\begin{array}{l}\text { Index of internal basic family } \\
\text { life quality (IIBFLQ) }\end{array}$} & Food & $\mathrm{X} 1$ \\
\hline & & & Clothing & $\mathrm{X} 2$ \\
\hline & & & Live & $\mathrm{X} 3$ \\
\hline & & & Equipment & $\mathrm{X} 4$ \\
\hline & & & Traffic and communication & $\mathrm{X} 5$ \\
\hline & & \multirow{5}{*}{$\begin{array}{l}\text { Index of internal additional } \\
\text { family life quality (IIAFLQ) }\end{array}$} & Cars & $\mathrm{X} 6$ \\
\hline & & & Entertainment & $\mathrm{X} 7$ \\
\hline & & & Health care & $\mathrm{X} 8$ \\
\hline & & & Insurance & X9 \\
\hline & & & Mansions & $\mathrm{X} 10$ \\
\hline & & \multirow{3}{*}{$\begin{array}{l}\text { Index of internal spiritual family } \\
\text { life quality (IISFLQ) }\end{array}$} & Wealth & $\mathrm{X} 11$ \\
\hline & & & Marriage & $\mathrm{X} 12$ \\
\hline & & & Work & $\mathrm{X} 13$ \\
\hline & \multirow{11}{*}{$\begin{array}{l}\text { Index of } \\
\text { external social } \\
\text { life quality } \\
\text { environment } \\
\text { (IESLQE) }\end{array}$} & \multirow{4}{*}{$\begin{array}{l}\text { Index of external basic social } \\
\text { life quality environment } \\
\text { (IEBSLQE) }\end{array}$} & Water & $\mathrm{X} 14$ \\
\hline & & & Gas & $\mathrm{X} 15$ \\
\hline & & & Road & $\mathrm{X} 16$ \\
\hline & & & Bus & $\mathrm{X} 17$ \\
\hline & & \multirow{4}{*}{$\begin{array}{l}\text { Index of external additional } \\
\text { social life quality environment } \\
\text { (IEASLQE) }\end{array}$} & Medicine & $\mathrm{X} 18$ \\
\hline & & & Education & $\mathrm{X} 19$ \\
\hline & & & Knowledge & $\mathrm{X} 20$ \\
\hline & & & Environment & $\mathrm{X} 21$ \\
\hline & & \multirow{3}{*}{$\begin{array}{l}\text { Index of external spiritual social } \\
\text { life quality environment } \\
\text { (IESSLQE) }\end{array}$} & Equality & $\mathrm{X} 22, \mathrm{X} 26$ \\
\hline & & & Development & $\mathrm{X} 23, \mathrm{X} 24$ \\
\hline & & & Civilisation & $\mathrm{X} 25$ \\
\hline
\end{tabular}

$$
\begin{aligned}
& \text { ILQ }=\alpha_{1} \cdot I I F L Q+\alpha_{2} \cdot I E S L Q E \\
& \text { IIFLQ }=\beta_{1} \cdot I I B F L Q+\beta_{2} \cdot I I A F L Q+\beta_{3} \cdot I I S F L Q \\
& \text { IIBFLQ }=\gamma_{1} \cdot X 1+\gamma_{2} \cdot X 2+\gamma_{3} \cdot X 3+\gamma_{4} \cdot X 4+\gamma_{5} \cdot X 5 \\
& \text { IIAFLQ }=\gamma_{6} \cdot X 6+\gamma_{7} \cdot X 7+\gamma_{8} \cdot X 8+\gamma_{9} \cdot X 9+\gamma_{10} \cdot X 10 \\
& \text { IISFLQ }=\gamma_{11} \cdot X 11+\gamma_{12} \cdot X 12+\gamma_{13} \cdot X 13 \\
& \text { IESLQE }=\beta_{4} \cdot I E B S L Q E+\beta_{5} \cdot I E A S L Q E+\beta_{6} \cdot I E S S L Q E \\
& \text { IEBSLQE }=\gamma_{14} \cdot X 14+\gamma_{15} \cdot X 15+\gamma_{16} \cdot X 16+\gamma_{17} \cdot X 17 \\
& \text { IEASLQE }=\gamma_{18} \cdot X 18+\gamma_{19} \cdot X 19+\gamma_{20} \cdot X 20+\gamma_{21} \cdot X 21 \\
& \text { IESSLQE }=\gamma_{22} \cdot X 22+\gamma_{23} \cdot X 23+\gamma_{24} \cdot X 24+\gamma_{25} \cdot X 25+\gamma_{26} \cdot X 26
\end{aligned}
$$




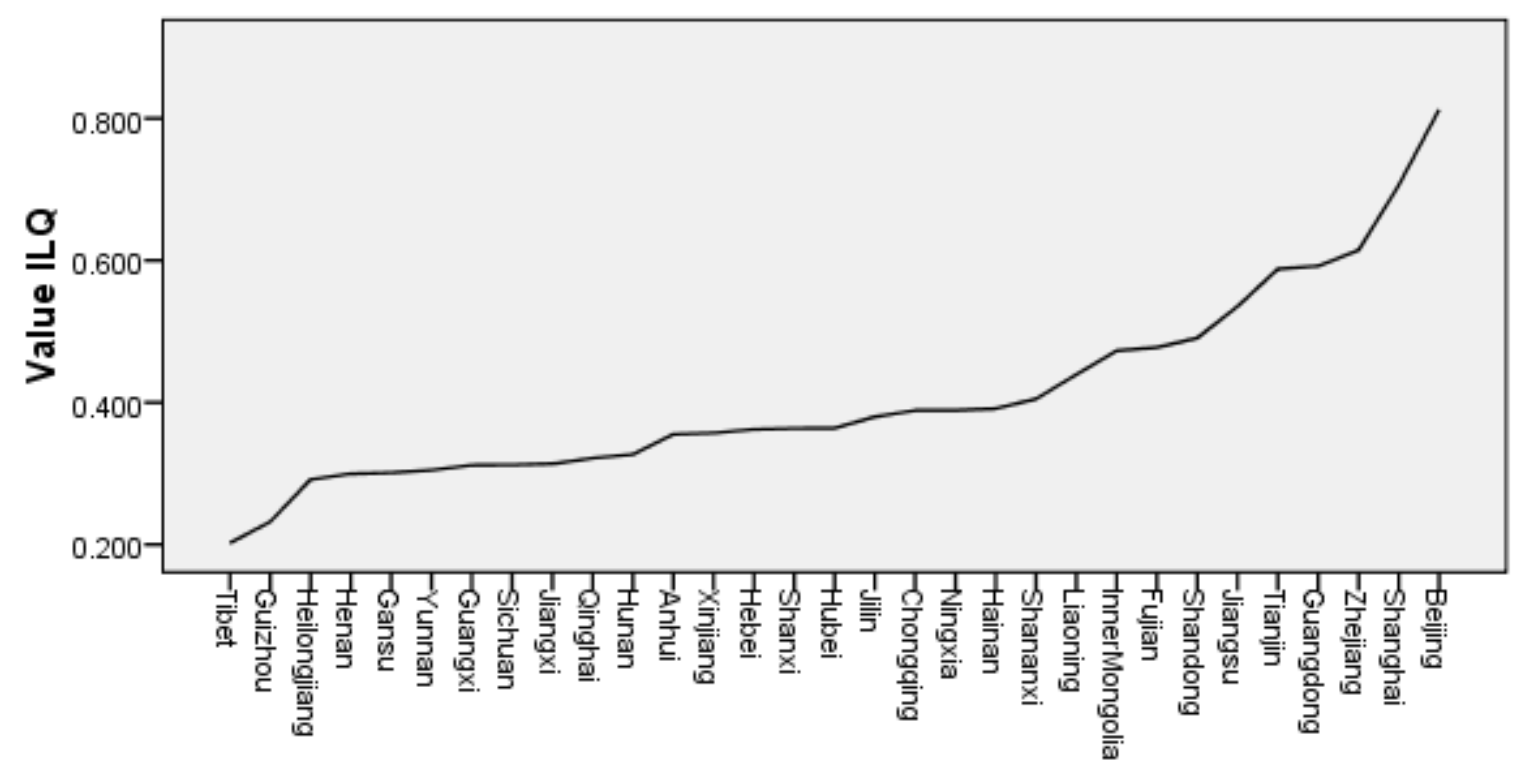

province

Fig. 2. Distribution of an index of quality of life in the Chinese provinces for 2013 (authors' result).

The ILQ unites internal factors (requirement of the population) and external factors (state resources). In Fig. 2, we can see that the top 5 of regions of China on an index of quality of life are Beijing, Shanghai, Zhejiang, Shandong and Tianjin. These provinces are characterised by a high standard of living. Gansu, Henan, Heilongjiang, Guizhou and Tibet are the top 5 of the worst regions on the quality of life. The received picture of distribution of regions is objective, as it is based on the integrated index in a complex considering state of the economy, a way of life of people and quality of the government.

Table 3. Comparison of integrated indexes ILQ and ratings of regions for 2013-2014

\begin{tabular}{|l|l|l|l|l|l|l|l|l|l|}
\hline Region (31) & $\begin{array}{l}\text { IQLA- } \\
13\end{array}$ & $\begin{array}{l}\text { IQLA- } \\
14\end{array}$ & $\begin{array}{l}\text { Rank- } \\
13\end{array}$ & $\begin{array}{l}\text { Rank- } \\
14\end{array}$ & Region & $\begin{array}{l}\text { IQLA- } \\
13\end{array}$ & $\begin{array}{l}\text { IQLA- } \\
14\end{array}$ & $\begin{array}{l}\text { Rank- } \\
13\end{array}$ & $\begin{array}{l}\text { Rank- } \\
14\end{array}$ \\
\hline Beijing & 0.778 & 0.810 & 1 & 1 & Hubei & 0.352 & 0.304 & 19 & 21 \\
\hline Tianjin & 0.567 & 0.496 & 5 & 6 & Hunan & 0.331 & 0.316 & 21 & 20 \\
\hline Hebei & 0.367 & 0.355 & 18 & 14 & Guangdong & 0.632 & 0.538 & 3 & 4 \\
\hline Shanxi & 0.374 & 0.329 & 16 & 16 & Guangxi & 0.301 & 0.232 & 26 & 29 \\
\hline Inner Mongolia & 0.469 & 0.451 & 9 & 7 & Hainan & 0.391 & 0.354 & 12 & 15 \\
\hline Liaoning & 0.452 & 0.425 & 10 & 8 & Chongqing & 0.375 & 0.321 & 15 & 19 \\
\hline Jilin & 0.388 & 0.324 & 13 & 18 & Sichuan & 0.293 & 0.279 & 27 & 25 \\
\hline Heilongjiang & 0.313 & 0.292 & 23 & 22 & Guizhou & 0.206 & 0.225 & 30 & 30 \\
\hline Shanghai & 0.619 & 0.608 & 4 & 3 & Yunnan & 0.314 & 0.283 & 22 & 23 \\
\hline Jiangsu & 0.554 & 0.519 & 6 & 5 & Tibet & 0.199 & 0.164 & 31 & 31 \\
\hline Zhejiang & 0.648 & 0.642 & 2 & 2 & Shaanxi & 0.380 & 0.359 & 14 & 13 \\
\hline Anhui & 0.332 & 0.281 & 20 & 24 & Gansu & 0.244 & 0.255 & 29 & 28 \\
\hline Fujian & 0.487 & 0.422 & 7 & 9 & Qinghai & 0.303 & 0.328 & 25 & 17 \\
\hline Jiangxi & 0.305 & 0.277 & 24 & 26 & Ningxia & 0.397 & 0.398 & 11 & 11 \\
\hline Shandong & 0.477 & 0.419 & 8 & 10 & Xinjiang & 0.371 & 0.372 & 17 & 12 \\
\hline Henan & 0.259 & 0.263 & 28 & 27 & & & & & \\
\hline
\end{tabular}

For the purpose of additional approbation of the author's approach to the formation of integrated estimated indexes (a social and economic infrastructure and quality of life of the population), calculation on model 'a method of the main things a component' (Aivazian 2012) is executed. Result of experimental modelling on model (Aivazian 2012) is a file of integrated indicators $\mathrm{II}_{j}(\mathrm{j}=1,2, \ldots$, 31 ) and rankings' number of regions (on decrease in the value of $\mathrm{II}_{j}$ ). After comparison of results 
(Figure 2, Table 3), it is possible to speak about the correctness of practical application of author's model ILQ.

The dependence analysis between the level of development of social and economic infrastructure and the level of quality of life of population. Now, a lot of authors in the world economic science (e.g. Kondratyev 2010, Kularathe 2006) notice that the condition of a social and economic infrastructure influences the economic growth of territories, and through it, the quality of life of the population. Thus authors notice (McKinsey, 2009) that it is possible to measure the effect (in the monetary form) only with a delay $\log$ in 5-10 years. However, quantitative results about such influence are not published yet, because of objective difficulties. In this work, an attempt to confirm the dependence hypothesis between a condition of an infrastructure and a standard of living of citizens through the comparison of integrated estimated indexes of territories is undertaken. We estimate the influence of an infrastructure on quality of life through comparison of the ordered numbers of objects (regions), that is, ranks, within available time numbers (periods).

For the maintenance of reliability and validity of conclusions, the following are the necessary conditions for planning of computer experiments:

Table 4. Summary rating of regions: IDSEI $(2009,2010)$ and ILQ $(2013,2014)$

\begin{tabular}{|c|c|c|c|c|c|c|c|}
\hline Region & IDSEI09 & IDSEI10 & $(09+10)$ & ILQ13 & ILQ14 & $(13+14)$ & Summary \\
\hline Beijing & 18 & 23 & 21 & 1 & 1 & 1 & 7 \\
\hline Tianjin & 24 & 25 & 25 & 5 & 4 & 4 & 11 \\
\hline Hebei & 16 & 17 & 17 & 18 & 15 & 16 & 16 \\
\hline Shanxi & 23 & 24 & 24 & 17 & 18 & 17 & 25 \\
\hline Inner Mongolia & 3 & 3 & 3 & 9 & 7 & 7 & 1 \\
\hline Liaoning & 26 & 26 & 26 & 10 & 10 & 10 & 21 \\
\hline Jilin & 9 & 8 & 7 & 15 & 21 & 19 & 10 \\
\hline Heilongjiang & 5 & 5 & 5 & 29 & 27 & 29 & 19 \\
\hline Shanghai & 31 & 31 & 31 & 2 & 2 & 2 & 17 \\
\hline Jiangsu & 12 & 7 & 10 & 6 & 5 & 6 & 3 \\
\hline Zhejiang & 15 & 18 & 16 & 3 & 3 & 3 & 6 \\
\hline Anhui & 14 & 14 & 14 & 20 & 22 & 22 & 22 \\
\hline Fujian & 13 & 13 & 13 & 8 & 9 & 9 & 8 \\
\hline Jiangxi & 8 & 10 & 9 & 23 & 26 & 24 & 18 \\
\hline Shandong & 6 & 6 & 6 & 7 & 8 & 8 & 2 \\
\hline Henan & 7 & 11 & 8 & 28 & 23 & 25 & 14 \\
\hline Hubei & 11 & 12 & 12 & 16 & 19 & 18 & 12 \\
\hline Hunan & 17 & 15 & 15 & 21 & 20 & 21 & 23 \\
\hline Guangdong & 10 & 9 & 11 & 4 & 6 & 5 & 4 \\
\hline Guangxi & 28 & 28 & 28 & 25 & 29 & 28 & 30 \\
\hline Hainan & 22 & 19 & 20 & 12 & 14 & 13 & 15 \\
\hline Chongqing & 29 & 29 & 29 & 14 & 17 & 14 & 27 \\
\hline Sichuan & 20 & 16 & 18 & 24 & 24 & 23 & 26 \\
\hline Guizhou & 30 & 30 & 30 & 30 & 30 & 30 & 31 \\
\hline Yunnan & 21 & 22 & 22 & 26 & 28 & 26 & 29 \\
\hline Tibet & 2 & 1 & 1 & 31 & 31 & 31 & 13 \\
\hline Shaanxi & 27 & 27 & 27 & 11 & 12 & 11 & 24 \\
\hline Gansu & 19 & 21 & 19 & 27 & 25 & 27 & 28 \\
\hline Qinghai & 4 & 4 & 4 & 22 & 16 & 20 & 9 \\
\hline Ningxia & 25 & 20 & 23 & 13 & 11 & 12 & 20 \\
\hline Xinjiang & 1 & 2 & 2 & 19 & 13 & 15 & 5 \\
\hline
\end{tabular}

Condition 1. Comparability of initial information based on all regions, for all years of the chosen period, for all applied settlement techniques and mathematical models.

Condition 2. Sufficient extent of the time period for revealing the tendency of the dependence of quality of life on infrastructure. 
Condition 3. Volumes of sample of investigated objects (quantity of provinces in each number of a rating) should coincide.

For the increase of reliability of conclusions of the comparative analysis, calculation of indexes and ranging of regions are executed also on a method of the main things a component, which has shown close results. In Table 4, the information base for the comparative analysis is shown.

\section{Results of Modelling}

Now in the developing China, developments of a social and economic infrastructure and improvement of quality of life are not synchronous. The close order of values in a rating of quality of an infrastructure and quality of life means that the infrastructural investments of previous years are enough for increasing the standard of living now. And on the contrary, the presence of a return order of ranks testifies to insufficiency made before efforts on infrastructure development. We should consider that the qualitative effect of infrastructural investments on the population affects in some years. Values of indexes have defined system rankings numbers of objects (ratings of the Chinese provinces), which, in dynamics on years, indirectly show changes in an infrastructure condition, in initial year of the investigated period and in a population's standard of living, in a year finishing, as reaction (or effect) on the saved up infrastructural investments. In other words, we can track change of 'site' of region in rankings numbers for a number of years, that is, see how integrated quality of region has changed in this time.

The following result is the definition of regions with 'the worst' ratings on an infrastructure condition (in initial year of a 5-year period) and the quality of life (last year of the same 5-year period). If movement to the best is not present (there is no rating increase), this region should be investigated in detail, as priority, for the expansion of the state infrastructural investments - in a following planned period. For example, apparently from Table 4, priority applicants for the investments into an infrastructure during the period 2015-2020 are the Guangxi and Guizhou provinces (with "the worst" rating). On the contrary, in the current 5-year period, capital regions (district Beijing and district Shanghai) effectively used the saved up infrastructural investments into previous years and have achieved the best standard of living of the population by the end of the period. (We will add that the effect will affect in the following years).

The executed research on the limited statistical sample provided by the comparable data confirms the hypothesis about dependence of a level of development of an infrastructure and quality of life. The summary integrated index of quality of life (Table 4) defines a rating of objects (regions) - 'following the results of a 5-year period of development of an infrastructure'. The received summary rating of regions following the results of a 5-year period can serve as additional information support for the central government management, with a view of a substantiation and acceptance of administrative decisions in the field of an infrastructural policy on intermediate term prospect.

\section{Conclusions}

The new technique of the complex comparative analysis of rank indicators of regions (rating positions), based on the levels of development of an infrastructure and quality of life of the population, with a $\log$ of delay of 5-10 years, can be applied to experimental acknowledgement of an actual scientific hypothesis in the modern economic theory: 'About the presence of dynamic influence of a condition of an infrastructure of territories on quality of life of the population'.

The offered mathematical models and algorithms have important application for the state investment policy. Owing to the limitation of resources, the major problems of state planning of infrastructural investments are the establishment of priorities of directions of investment of regions, and the economic and geographical sequence of consumers of regions. For the decision of this problem, it is necessary to have an objective estimation of the level of development of a social and economic infrastructure of regions to do their rating. On the other hand, the state managers should lean against an objective estimation of a standard of living of the population of territories, it is ratings of regions. Comparison of two ratings of regions of the country based on the level of development of an 
infrastructure and on a population standard of living is a validity and expediency of the largest longterm state investments in infrastructural projects.

The further expansion of scale of experimental modelling, that is, use of possibilities of details of national statistics of the different countries in 10-15 years, will yield additional results for the scientific economic theory and application in management. Authors invite colleagues to take part in researches.

\section{References}

Aivazian S.A. (2012). Analysis of the Quality of Life and Living Standards. Moscow: Science.

Aivazian S.A., Borodkin F.M. (2006). Social Indicators. Moscow: Unity-Dana.

Bakumenko L.P. (2011). Statistical Aspects of the Research of the Population Life Quality. Yoshkar-Ola: MarSTU.

Feng XiaoTian, Yi SongGuo. (2000). The Quality of Family Life in Urban Areas: The Indicators and the Structure. Sociological Studies. (4), 107-118.

Ilchenko A. (2014). Integrated Estimation of Social and Economic Infrastructure of Territory: Experimental Modeling. International Journal of Business, Humanities and Technology, (2), 90-97.

Ilchenko A., Ma Jun. (2012). Integrated Estimation of a Level of Development of a Social and Economic Infrastructure of Region. Modern High Technologies. The Regional Appendix, (4), 37-43.

Kondratyev B. ( 2010). Infrastructure as the Factor of Economic Growth. [Accessed 10.11.2010]. Available from Internet: http: //www.perspektivy.info

Kularathe C. (2006). Social and Economic Infrastructure Impacts on Economic Growth. UCT School of Economics Staff Seminar Series.

Lin Nan, Wang Ling, Pan YunKang.(1987). Structure and Index of the Life Quality-the Material Analysis of the Thousand Family Surveys in Tianjin in 1985. Sociological Studies. (6), 73-89.

Lu ShuHua, Wei LuYing. (1992). The Action Mechanism of the Subjective and Objective Index of Life Quality. Social Sciences in China. (1), 121-136.

Mc Kinsey Quarterly. (2009). The Right Way to Invest in Infrastructure.

Morris M.D. (1980). The Physical Quality of Life Index (PQLI). Development digest. (1), 95-109.

National Bureau of Statistics of the People's Republic of China. (2013). China Statistical Yearbook -2013. Beijing: China Statistics Press.

National Bureau of Statistics of the People's Republic of China. (2014). China Statistical Yearbook -2014. Beijing: China Statistics Press.

Verbik M. (2008). A Guide to Modern Econometrics. The Scientific Book.

Xiang Xiao Gang. (2015). Factor Analysis Method of Chinese Provinces Life Quality Evaluation. Modern High Technologies. The Regional Appendix, (3), 142-152.

Xiang Xiao Gang \& Ilchenko A. (2013). Social and Economic Infrastructure as the Tool of Alignment of Economic Development of Regions of China. Modern High Technologies. The Regional Appendix, (1), 66-70.

Zheng ZongSheng, Wu SuYao, He ChuanQi. (2006). The Comparison of the Quality of Life of the 120 Countries in the World. Theory and Modernization. (4), 15-20.

Zhou ChangCheng. (2001). Social development and life quality. Beijing: Social Sciences Academic Press, 52-60. 